\title{
After Covid-19: economic security in EU-Asia connectivity
}

\section{Tobias Gehrke ${ }^{1}$}

Published online: 26 May 2020

C) Springer-Verlag GmbH Germany, part of Springer Nature 2020

\section{The geopolitics of interdependence}

Covid-19 vividly demonstrates the vulnerabilities of a globalized economy. At the apex of the crisis in Europe, supply of life-saving medical equipment could not be guaranteed. Governments around the globe rushed to restrict medical exports for fears of national shortages, threatening the ability of other governments in the global economy to effectively tend to their immediate health security needs.

The vulnerable mechanism underwriting globalization? An interdependent global economy in which individual dependencies can expose states to vulnerabilities in times of crisis. Deep interdependencies are not new. Neither is periodic mistrust in them. German economist Max Sering wrote in 1900: "It has been wrongly contended that in the economic intercourse of nations the dependence is always a mutual one. [There] exists between national economies relations of exploitation and of subjection." Covid-19 stimulated this simmering angst about a loss of national autonomy.

Though unmatchable in its global punch, the health pandemic is not the only crisis the interdependent global economy faces. Geopolitics, too, is not conducive to smooth operations. As Sering and his peers already warned over a century ago, powers can weaponize dependencies, should this be in their political interest. This age-old form of statecraft is en vogue once again: access to finance, the flow of investment, the export of technology, chemical inputs - or, indeed, the export of live-saving drugs during a pandemic. The great powers instrumentalize everything and strategic trade networks are particularly vulnerable.

International rules, which have curbed this statecraft rather successfully in past decades, have seen better days. Take the World Trade Organization (WTO). Its ability

Tobias Gehrke is a research fellow in the Europe in the World programme at the Egmont - Royal Institute for International Relations in Brussels. He is also an early-stage researcher in the EU-funded Marie Curie Project "EU Trade and Investment Policy", through which he pursues a PhD on geo-economics at Ghent University.

Tobias Gehrke

t.gehrke@egmontinstitute.be

1 Egmont Institute, Brussels, Belgium 
to work - that is to de-politicize trade flows and settle trade brawls through law, not power-is in a coma. Its lifeline, a new multilateral compromise on all its functions, looks all too distant. Will the corona crisis embolden the global community to overcome their differences at the WTO? One EU initiative provides a lifeline for the optimistically minded. The crisis may however also accelerate the opposite trend of fragmentation and confrontation.

All this does not spell the end of globalization. In the big picture, global economic interdependence is here to stay. The question before governments today is where the balance lies between, on the one hand, the vast economic benefits of deep interdependence, and, on the other hand, the necessary resilience they demand from these networks, in order to place parts of their security - national, economic, health, or otherwise - into their custody. Without resilience - a level of control and certaintygovernments will tip the balance towards the national agenda. This would be an unfortunate development. But while the transformation of globalization seems inevitable, its path is not locked to end in regressive nationalism.

\section{Economic security revisited}

Already Adam Smith in Wealth of Nations famously considered "defense [...] of much more importance than opulence." The defence of citizens' health may be a more obvious reason for states to intervene in global markets. Defending sustainability and our climate goals too has gained in public support, especially in Europe. State action, for example with interventionist tools proposed as part of the European Green Deal, is gaining momentum (albeit disputed). Things get more complicated for other risks, such as those posed by emerging technologies. Artificial intelligence, for example and its input - data - is not only considered as an economic opportunity, but also as a disruption to security competition and societal futures. It is but one example in a ballooning list of strategic technologies for which powers are less willing to expose themselves to the potential risks of global networks - or rival governments. The US and China technology competition is anchored in this reality. But its logic is a global phenomenon.

Interdependence is a power struggle, not a mutual aid society. When we minimize that struggle through rules-based global governance, as we have quite successfully done in past decades (and, with exceptions, have excelled at in European integration), mutually beneficial outcomes are of course possible. But despite growing demand for global rules to govern an interdependent world, the latter has hastily outrun the former. From digital, to technology, trade, investment, competition or climate governance, power is distributed in more hands, both state and nonstate, than ever before. "The world today is simply not conducive to being shaped", Richard Haas inferred in a recent essay.

Governments intervene in economic networks, chiefly to reconfigure supply chains and decrease dependencies on single suppliers in search for more economic securityeven if that might come at an economic cost. This is a global phenomenon. In Japan, the government recently issued a $\$ 2$ billion subsidy for its manufacturing companies to shift production out of China back to Japan or into Southeast Asia, amid growing concern over the geopolitical risks to its supply chains. The Chinese Communist Party, for its part, has been working hard to scale back its dependence on foreign supplies. 
The Made in China 2025 plan is explicitly designed to reduce Beijing's dependence on foreign technology and make critical commercial supply lines self-sufficient. The USA too unleashed a heavy-handed retooling of policy by attempting with sticks and carrots to keep manufacturing onshore, while limiting technology supplies to adversaries. Countries around the globe, motivated by a growing range of security concerns, have introduced restrictions on foreign investments in their economies-from Europe, to India, Canada, Australia, the USA, Japan, Korea and others.

For the European Union, initial adaptation has been slower, but it now experiences a major propulsion in the wake of Covid-19. The pandemic evidenced to policymakers that the availability of medical supplies cannot be fully dependent on the efficiency rules of the global economy. The creation of an EU strategic stockpile for medical equipment and a new EU pharmaceutical strategy is directly addressing this supply issue. At the same time, the Commission announced to support negotiation of a plurilateral agreement, with the grandiose goal of "permanent liberalisation of tariffs on medical equipment."

Beyond health policy, the EU also curates a list for critical raw materials, for which reliable and unhindered access is vital to the EU economy and the development of digital technologies (e.g. cobalt for batteries). Securing and diversifying access to these materials in foreign markets via trade agreements, for example, is contrasted by several domestic EU initiatives to shore up local production, bankroll relevant technology innovation, produce better data over local availability and coordinate with the Circular Economy Strategy.

Horizontally, economic security is also addressed in the recently published EU industrial strategy. In it, the Commission notes cautiously, but rightly, that next to critical materials, reducing dependencies in "technologies, food, infra-structure, security and other strategic areas" is critical to economic security. An EU investment screening regulation, the EU 5G toolbox, and several other new financial and regulatory instruments are surfacing. The EU still lacks the power to approve or block foreign investments. But it urged Member States to "make full use of tools available to them $[\ldots]$ to preserve EU companies and critical assets [...] that are essential for our security and public order." Germany, for example, set up a bailout fund to "temporarily" take over struggling German companies, before foreigners snatch up strategic assets, and reformed its investment review methodology.

While the crisis demands swift action, a more comprehensive approach to economic security will be required of Europe and of Asia. The availability of defensive armour is part of this approach. But it is only one side of the coin. The other side is stepping up international cooperation, avoiding Europe's response from becoming a frenzy of economic nationalism and protection of legacy industries. It will require a new form of economic cooperation: one which builds resilience directly into the design of economic integration.

\section{Making economic security a pillar of EU-Asia connectivity}

"We need to look at how to build resilient supply chains, based on diversification," EU Commissioner for Trade Phil Hogan declared in April. Resilience, in 
other words, does not have to contradict an international economic policy of openness and cooperation.

Hogan is right. But diversification for the sake of diversification will not increase resilience by default, just as onshoring or nationalization would not do so either. Supply chain resilience can only come through a trusted network of actors who can be reliable partners in cases of crisis - partners with whom we can transparently develop common risk coordination mechanisms, methods and standards for assessment, share information and expectations, and have an active dialogue with governments, firms, and investors. Economic security, in short, must become a staple of political cooperation.

There are multilateral and plurilateral fora for this. The United Nations Industrial Development Organization, the WTO or the OECD are examples. European and Asian states should retain multilateral efforts where possible. But proactive action is required. The EU-Asia Connectivity Strategy, which already seeks to foster sustainable and rules-based economic networks in Eurasia, could be this instrument by integrating economic security and resilience closely into its strategy.

The 2018 Strategy, to be sure, has drawbacks. It still lacks explicit funding and has so far fallen short of bundling European external investment, infrastructure projects, private investment and financial instruments into a coherent platform. Other than Japan, it has also not been able to create serious 'connectivity partnerships' with other major players. Unlike the Belt and Road Initiative (BRI), it also suffers from the lack of a geopolitical narrative of what the EU is seeking to achieve, where it wants to do so, and how it relates to the other powers' ambitions. In this absence, it is hardly surprising that not few consider it another apolitical, technical, bureaucratic exercise.

These shortcomings need to be addressed, and quickly. For this to happen, Member States and the EU institutions themselves need to see Connectivity for what it can be: a comprehensive offer for a new era of globalization - one which is more realistic about the risks of an interdependent economy without sacrificing its benefits. Risks are varied. They include ownership of critical sectors, infrastructure and processes; espionage; critical raw materials and energy dependence; single-supplier dependence; government intervention; or the erosion of a strong industrial and technological base.

On the operational level, two courses of action stand out. First, the EU, in coordination with all relevant actors, needs to start mapping out supply chains of our critical products, industries and infrastructure and the linkages between them. No easy task, as firms often do not have a full picture of their supply chains themselves. We have a better picture for critical raw materials and energy, while the defence sector is traditionally more attuned to supply chain risks. There is much to learn, as without this knowledge, policymakers will remain bound to educated guesses over possible choke points in global supply chains and cannot tailor strategic redundancies to our needs.

Second, building a network of trusted partners must mean to have a political engagement, rather than an overly technical or legal exercise (which the EU all too often personifies in its external affairs). Additionally, integrating economic security in connectivity will require an active dialogue with governments, firms and investors, in order to transparently develop common risk coordination mechanisms, methods and standards for assessment, and the sharing of information and expectations. The goal should be to incentivize companies to transform their supply chains within the connectivity framework, without having to prepare for every possible risk. 


\section{Conclusion}

Globalization is not dead. But we will not go back to the world that was, where security and resilience to economic interdependence was an afterthought. In this new era, economic integration must build resilience directly into its design, or risk the destructive forces of economic nationalism. While protectionist and nationalist motivations will compete for attention, the genuine responsibility to protect critical sectors, critical infrastructure and critical processes from the risks of interdependence does not have to sacrifice EU-Asia economic integration. Interdependence is here to stay. How we manage it is what matters.

Publisher's note Springer Nature remains neutral with regard to jurisdictional claims in published maps and institutional affiliations. 